\title{
Isolation and Selection of Fungi for Degrading Saturated Hydrocarbons, Aromatic Hydrocarbons and NSO Compounds
}

\author{
Danusia Ferreira Lima, Olivia Maria Cordeiro de Oliveira, Regina Maria dos Santos Geris, \\ Jorge Alberto Trigüis, Antônio Fernando de Souza Queiroz, Manoel Jerônimo Moreira Cruz, \\ Isana Souza Barreto
}

Environmental Studies Center, Geosciences Institute, The Bahia Federal University, Salvador, Brazil

Email: danbio28@gmail.com

How to cite this paper: Lima, D.F., De Oliveira, O.M.C., Dos Santos Geris, R.M., Trigüis, J.A., De Souza Queiroz, A.F., Cruz, M.J.M. and Barreto, I.S. (2017) Isolation and Selection of Fungi for Degrading Saturated Hydrocarbons, Aromatic Hydrocarbons and NSO Compounds. Open Journal of Yangtze Gas and Oil, 2, 10-26. https://doi.org/10.4236/ojogas.2017.21002

Received: December 15, 2016 Accepted: January 18, 2017

Published: January 23, 2017

Copyright $\odot 2017$ by authors and Scientific Research Publishing Inc. This work is licensed under the Creative Commons Attribution International License (CC BY 4.0).

http://creativecommons.org/licenses/by/4.0/

\begin{abstract}
Petroleum hydrocarbons are recalcitrant contaminants that have various impacts on the natural ecosystem. Microorganisms have been widely used in recent years to remove the hydrocarbons that are present in crude oil. The objective of this research was to isolate and select microorganisms that have the potential to degrade hydrocarbons present in mangrove sediments. In present study, we have isolated fungi from clean sediment contaminated with different fractions (i.e., saturated hydrocarbons, aromatic, and no hydrocarbon compounds (NSO)) of two types of oil. There were two types of oxidation tests were performed: one in multi well plates and the other in stirring and temperature control. Screening tests were conducted to detect the biodegradation of petroleum fractions with 72 fungal isolates over a period between 12 and 48 hours. With the two oxidation tests, the 2,6-dichlorophenol-indo phenol (DCPIP) indicator made it possible to select fungi with the potential to degrade the three main fractions of oil in the Reconcavo and Campos Basins. It was observed that the fungal isolates in the cleaned sediment were able to oxidize the three fractions of both types of oil. It was also concluded that some isolated strains oxidize oil faster and more efficiently than others. The formation of a consortium with the isolated consortium was a potential for the increase of the degradation of oil in the environment.
\end{abstract}

Keywords

Biodegradation, Hydrocarbons, Fungi, DCPIP Indicator

\section{Introduction}

Population development and the advance of industrialization, especially of the 
oil production chain, have had increased anthropogenic impacts on the biosphere. Because many sources of oil are needed to meet global demand, the processing, storage and transportation of oil are constantly required. As a result, oil spills are a major cause of soil and water pollution [1] [2] [3].

In addition to being composed of mixture of hydrocarbons, oil is composed of other organic compounds, such as organometallic nickel and vanadium complexes constituents, which are difficult to degrade the products [4].

Some microorganisms are armed with arsenals of enzymes that are able to use oil as a source of carbon and energy. These microorganisms have been the subject research on the isolation of species involved in oil degradation processes [5]. The main efficient microorganisms in reducing the oil spill from the environment are the bacteria (Alcanivorax and Rhodobactere) and the fungi (Aspergillus and Fusarium) [6] [7].

The biodegradation of petroleum hydrocarbons is a complex process and is directly related to the nature and amount of hydrocarbons. Studies have shown that the oil degradation rates also depend on weather and climate conditions [8]. For example, hydrocarbons in aquatic sediments are degraded slowly in the absence of light and oxygen.

Researchers [9] have reported that different factors influence the degradation of hydrocarbons. The limited availability of microorganisms in the environment is the main factor. Therefore, the mechanisms that bind these compounds to the substrate and their relative susceptibility to microbial attack are also key factors for the biodegradation process. This susceptibility may be generally classified as follows: linear alkanes $>$ branched alkanes $>$ aromatic $>$ cyclic alkanes [10].

Hydrocarbons are substrates that require an electron acceptor for the oxidation of a highly reduced initial stage [10]. A rapid screening technique is to use the redox indicator dye 2,6 dichlorophenol indophenol (DCPIP). A method using the redox indicator DCPIP was proposed to evaluate the potential for the microorganisms present to degrade hydrocarbons by using them as a substrate [11]. This is a redox reaction and it can be signaled by a color change in the indicator DCPIP from blue (oxidized form) to colorless (reduced form). The ability of a given microorganism to degrade the hydrocarbon is inversely proportional to the time required for the color of the DCPIP to turn. The test time is generally 24 to 48 hours.

One of the first fungal bioremediation studies reported that Aspergillus, Cephalosporium, and Penicillium cunninghamella were isolated from an estuarine environment and were capable of using oil as a sole source of carbon and energy [12]. They were identified as filamentous fungi and were isolated from soil contaminated with petroleum. The organisms' analysis showed that those with the ability to degrade hydrocarbons were grouped into four genera (Aspergillus, Penicillium, Paecilomyces and Fusarium) [13].

To assess the potential of fungi to efficiently degrade oil compounds, 72 fungal isolates were submitted to qualitative tests based on biological oxidation, which was evidenced by discoloration of the medium containing DCPIP [11] and was 
associated with the potential to degrade petroleum.

This technique follows the principle, and the indicator is the verification of the occurrence of biological oxidation of hydrocarbons, in which the DCPIP in the culture medium acts as the electron acceptor in the oxidation process [14].

Two types of oxidation tests were performed: one type is in multiwell plates and the other is in small vials (with stirring and controlled temperature). The change of the indicator occurred at different times for each individual test, which ranged between 12 and 48 hours. The isolates were tested with fractions (saturated hydrocarbons, aromatic and NSO compounds) of two types of oil: oil from the Recôncavo Basin and from the Campos Basin.

\section{Materials and Methods}

\subsection{Sampling Procedure}

Samples were obtained from a bioremediation experiment conducted in the Bioremediation Simulation Laboratory in the city of Candeias in Bahia, Brazil between September and October 2013. The substrate used to be subsurface sediment $(10-20 \mathrm{~cm})$ of mangroves located near the Landulfo Alves-Ba Refinery. The experiment was conducted in simulation units consisting of four glass tanks aquariums, each of which contained six beakers, which were tested for three treatments and a control. The test tubes were coated with cotton bags to prevent a high incidence of light, and a $10 \mathrm{~cm}$ aliquot of clean sediment (sediment without contamination by hydrocarbons) was added to each tube. The test tubes were placed in simulation tanks supported by a wooden support. An oxygenation pump was placed in each aquarium.

The pellet contained in the beakers was contaminated with fractions (saturated hydrocarbons, aromatic, and NSO compounds) of the Recôncavo Basin oil, equivalent to approximately $1 \%$ of the substrate by weight. The mixture was incubated for 30 days to permit adaptation of the biota to specialized xenobiotic degradation. A tide simulation for 2 hours/day was conducted throughout the experiment. The analyses were performed at the Laboratory of Biotechnology and Chemistry of Microorganisms and the Petroleum Laboratory at the Federal University of Bahia. Samples were collected at two periods, at time 0 and at time 30 , and were placed in previously decontaminated glass jars.

\subsection{Sample Processing}

Ten grams of soil were suspended in $95 \mathrm{~mL}$ of distilled water and $0.75 \mathrm{~g}$ of sodium chloride in Erlenmeyer flasks, which were then manually stirred.

\subsection{Quantification of the Microbiota}

The Sabouraud culture medium was used, a total of 5 serial dilutions were made, and $0.1 \mathrm{ml}$ was then transferred to the Petri dishes in duplicate. The dishes were incubated at $25^{\circ} \mathrm{C}$. Readings were based on the presence or absence of colony forming units (CFU) after seven days. 


\subsection{Isolation}

The method used to isolate filamentous fungi was dilution and coating [15].

\subsection{Obtaining Fractions of Oils}

Fractions of two types of oil, from the Recôncavo and Campos Basins, were obtained to observe the development of radial growth experiments through the vacuum chromatography method [16]. The three main fractions obtained from the oil included saturated hydrocarbons, aromatic hydrocarbons and NSO compounds.

\subsection{Obtaining Fractions of Oils}

Fractions of two types of oil, from the Recôncavo and Campos Basins, were obtained to observe the development of radial growth experiments through the vacuum chromatography method [16]. The three main fractions obtained from the oil included saturated hydrocarbons, aromatic hydrocarbons and NSO compounds.

\subsection{Selection of Fungi for Degrading Oil Fractions}

Isolated fungus control simulation units (ref 01) were tested with the three oil fractions (saturated hydrocarbons, aromatic and NSO compounds). The use of the redox indicator DCPIP (2,6-dichlorophenol-indophenol) was proposed to evaluate the potential for microorganisms to degrade hydrocarbons by using them as a substrate [11].

\subsection{Two Types of Tests Were Carried out}

Oxidation tests in multi well plates were in Figure 1 and Figure 2. To conduct the experiment, a standardized suspension of $10^{8} \mathrm{CFU} / \mathrm{mL}$ was added to each well of the multiwell plate. The following factors were varied in the experiment: $\mathrm{BH}$, carbon source (saturated hydrocarbons, aromatic and NSO compounds) and the redox indicator DCPIP. A negative control was also included. In abiotic wells (negative control), sterile water was added to replace the microbial suspension. The plates were incubated at $30^{\circ} \mathrm{C}$ and were visually observed at 0,24 and 48 hours. For fungi that showed the ability to utilize hydrocarbons as a substrate, there was discoloration in the middle of the well.

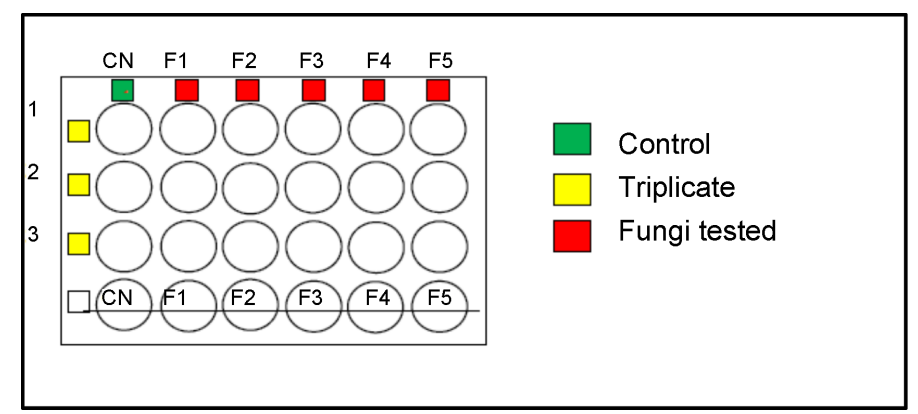

Figure 1. Scheme for selection of fungi in multi-well plates. 
Oxidation tests with agitation were in Figure 3. Only the isolates that showed greater than $50 \%$ oxidation in the previous test were tested with stirring. The experiments were performed in $20 \mathrm{~mL}$ vials with a medium Bushnell Haas carbon source (saturated hydrocarbons, aromatic and NSO compounds) and a microbial suspension. After 48 hours of acclimatization, including stirring at 200 $\mathrm{rpm}$ at $30^{\circ} \mathrm{C} \pm 1^{\circ} \mathrm{C}$, the redox indicator DCPIP was added to assess the time required for the biological oxidation of the tested fraction.

\section{Results and Discussion}

\subsection{Selection No. 1: 0xidation Test in Multiwell Plates}

In the screening test of the potential of fungi to degrade the oil fractions of the Recôncavo Basin (saturated hydrocarbons, aromatic and NSO compounds), 72 isolates of filamentous fungi were tested in multi well plates. The reading was performed at 24 and 48 hours. When the saturated hydrocarbon fraction was used as a carbon source, two of the filamentous fungi (R13 and S45) yielded a decolorized culture medium up to 24 hours after the addition of the DCPIP indicator, and R13 and S45 were bleached by approximately $25 \%$ and 50\%, respectively. When using the aromatic fraction, only one fungus (R1) was bleached by approximately 50\% 24 hours after the addition of the indicator. Regarding the NSO fraction, R31 was oxidized by approximately $50 \%$ at 24 hours after the addition of DCPIP, as shown in Figure 4.

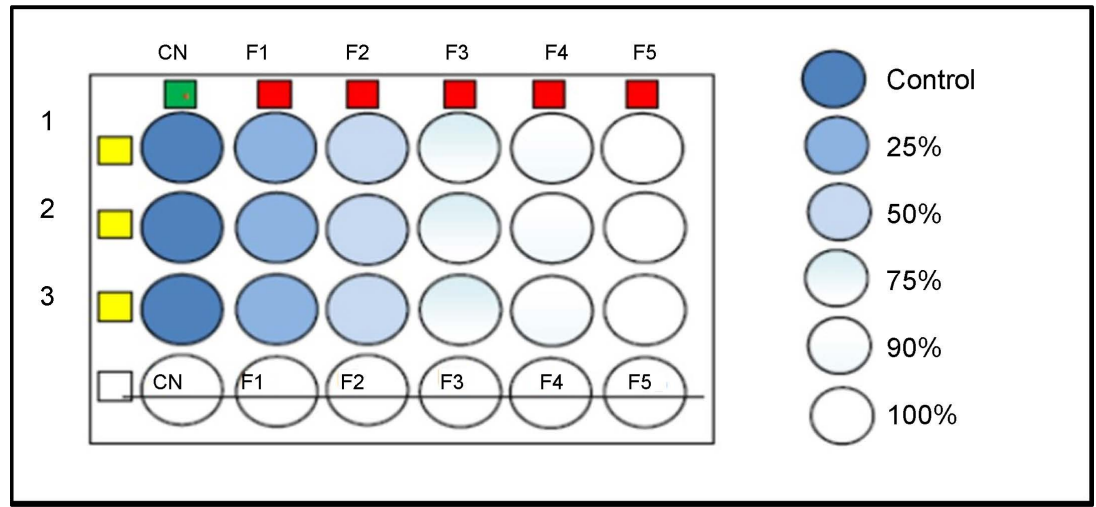

Figure 2. Discoloration classification (\%) for test 1.

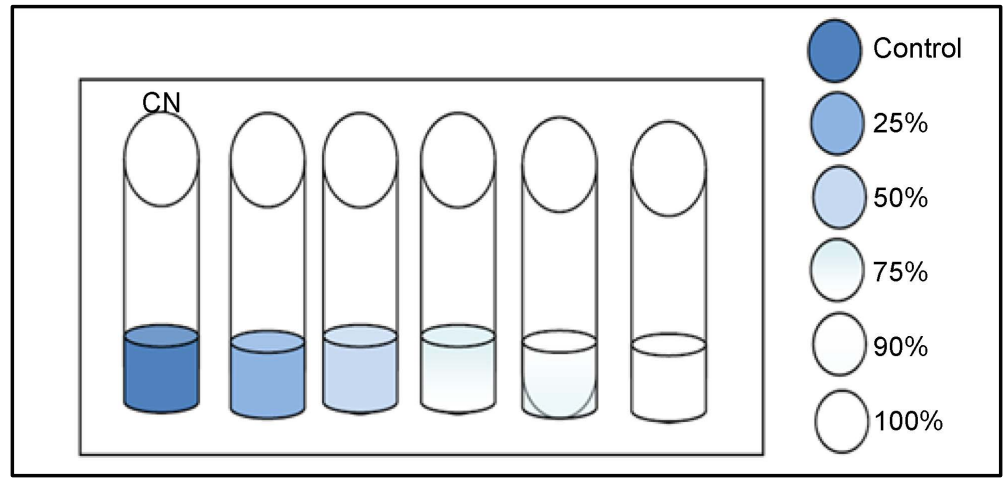

Figure 3. Discoloration classification (\%) for test 2. 

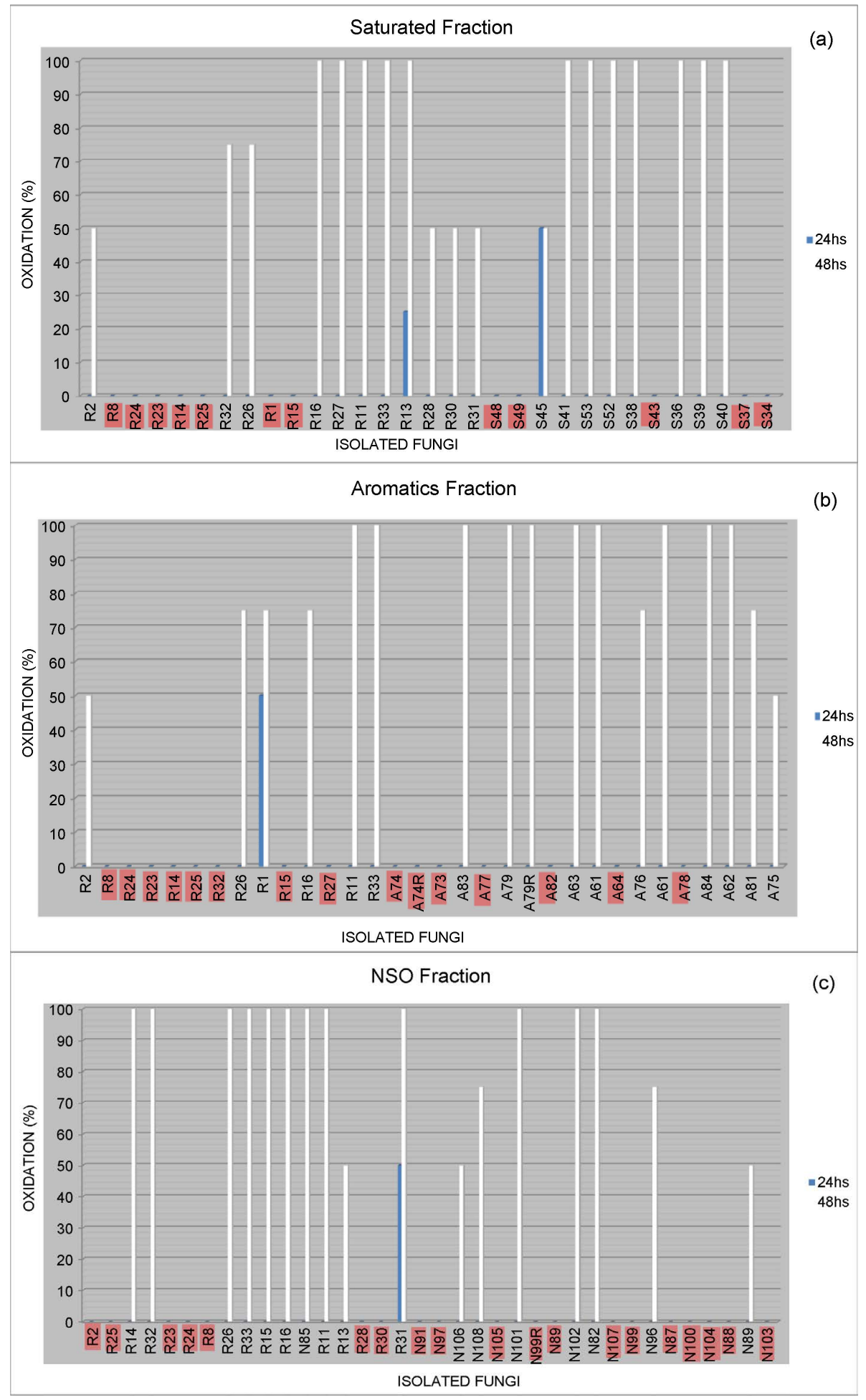

Figure 4. The fungi tested for its ability to oxidize oil from the Recôncavo Basin: (a) the saturated fraction, (b) the aromatic fraction, and (c) the NSO fraction.

We tested 23 strains of filamentous fungi with the potential to degrade petroleum products including diesel, gasoline, kerosene and bunker, where $4 \%(1 / 23)$ $4 \%(1 / 23) 23 \%(6 / 23)$ and $13 \%(3 / 23)$ of filamentous fungi decolorized the culture medium up to 24 hours after the addition of the DCPIP when the petroleum 
products mentioned above were used as the carbon source, respectively [17]. Despite the small percentage presented in the results, isolated fungi from environments contaminated with oil indicate that they play an important role in the degradation of the oil spilled into the environment [7].

After 48 hours, when using the aromatic fraction, R2 and A75 oxidized approximately 50\%; R26, R1, R16, A76 and A81 oxidized approximately 75\%; and R11, R33, A83, A79, A79R, A63, A61, A84 and A62 decolorized approximately $100 \%$ (Figure 4(b)).

Regarding the NSO fraction, R13, N89 and N106 oxidized approximately 50\%; N96 and N108 oxidized approximately 75\%; and R14, R32, R26, R33, R15, R16, N85, R11, R31, N101, N102 and N82 decolorized approximately 100\% after 48 hours (Figure $4(\mathrm{c})$ ).

Isolates R8, R24, R23, R14, R25, R1, R15, R32, R27, R28, R30, S48, S49, S43, S37, S34, A74, A74R, A73, A77, A82, A64, A78, N97, N91, N105, N99R, N89, N107, N99, N100, N87, N104, N88 and N103 showed no oxidative activity in tests with oil fractions of the Recôncavo Basin (Figures 4(a)-(c)).

Within 48 hours after the addition of DCPIP, 19 isolates decolorized the culture medium when using the saturated fraction. Of those, R2, R32, R26, R28, R30, R31, and S45 decolorized approximately 50\%; and R16, R27, R11, R33, R13, S41, S53, S52, S38, S36, S39 and S40 decolorized 100\% of the culture medium (Figure 5).

Only 16 strains completely bleached the culture medium after $24 \mathrm{~h}$ of incubation at $30^{\circ} \mathrm{C}$. The other strains decolorized the culture medium after periods of 48 hours (8\%) and $72 \mathrm{~h}(84 \%)$.

It is noteworthy that were 34 isolates obtained with an oxidative capacity of $100 \%$ after 48 hours. For this screening test, a $25 \mu \mathrm{L}$ suspension of fungal spores was used, and concentrations in the suspensions were determined. The number of spores is expressed in $10^{5} \mathrm{CFU}$, as reported in Table 1.

With these data, it was found that the capability to oxidize organic compounds is not linked to the amount of spores produced by the isolates. A comparison of the data in Table 1 with Figure 5 indicates that some isolates produce fewer spores and are able to oxidize approximately $100 \%$ of the culture medium. For example, the fungus A79 produces $1.0 \times 10^{5}$ spores and oxidizes approximately

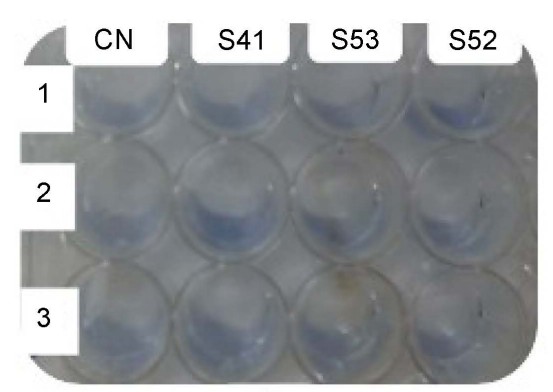

(a)

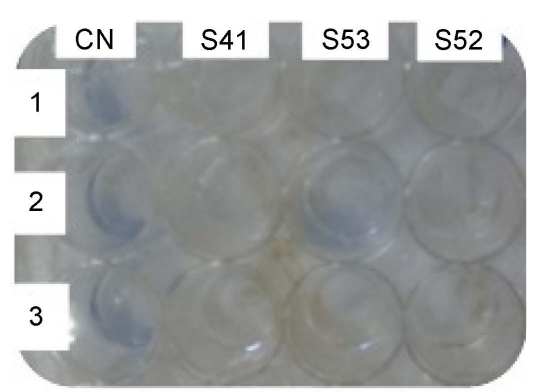

(b)

Figure 5. Illustration of the change in indicator color after 48 hours for two fungi tested for oxidation of the oil from the Recôncavo Basin: (a) time 0, and (b) after 48 hours. Source: the author. 
$100 \%$ spores of the aromatic fraction. In contrast, the fungus A63, which produces $310.5 \times 10^{5}$ spores, also oxidizes $100 \%$ of the same fraction.

It was observed that among the tested fungal isolates, four were able to decolorize the culture medium when tested with the three fractions after the addition of DCPIP. In Figure 6, it can be seen that the fungal isolates R16, R11 and R33 oxidized $100 \%$ when tested with the three fractions. The isolate R26 was also noted as yielding a higher degree of oxidation of the NSO fraction.

Table 1. Values of quantitative spore solution used in the oxidation test oil to the bowl Recôncavo.

\begin{tabular}{|c|c|c|c|c|c|}
\hline SAT & Spores $\left(\mathrm{UFC} \times 10^{5}\right)$ & ARO & Spores $\left(\mathrm{UFC} \times 10^{5}\right)$ & NSO & Spores $\left(\mathrm{UFC} \times 10^{5}\right)$ \\
\hline R2 & 83.75 & $\mathrm{R} 2$ & 83.75 & R14 & 44.00 \\
\hline R32 & 1.25 & R26 & 29.00 & R32 & 1.25 \\
\hline R26 & 29.00 & R1 & 2.50 & R26 & 29.00 \\
\hline R16 & 269.5 & R16 & 269.50 & R33 & 0.00 \\
\hline R27 & 50.00 & R11 & 169.00 & R15 & 8.25 \\
\hline R11 & 169.00 & R33 & 0.00 & R16 & 269.50 \\
\hline R33 & 0.00 & A83 & 250.00 & R11 & 169.00 \\
\hline $\mathrm{R} 13$ & 25.75 & A 79 & 1.00 & R13 & 25.75 \\
\hline R28 & 0.00 & A 79R & 1.00 & R31 & 5.25 \\
\hline R30 & 153.5 & A63 & 310.5 & N94 & 1.50 \\
\hline R31 & 0.00 & A80 & 121.5 & N101 & 57.75 \\
\hline S45 & 47.00 & A76 & 14.75 & $\mathrm{~N} 102$ & 104.25 \\
\hline S41 & 44.25 & A61 & 324.00 & N82 & 0.00 \\
\hline S53 & 193.00 & A84 & 89.50 & N96 & 0.75 \\
\hline S52 & 86.50 & A62 & 6.00 & N89 & 56.00 \\
\hline S38 & 175.50 & A81 & 45.25 & N85 & 0.00 \\
\hline S36 & 134.25 & A75 & 94.50 & N106 & 286.25 \\
\hline S39 & 31.00 & - & - & - & - \\
\hline S40 & 6.00 & - & - & - & - \\
\hline
\end{tabular}

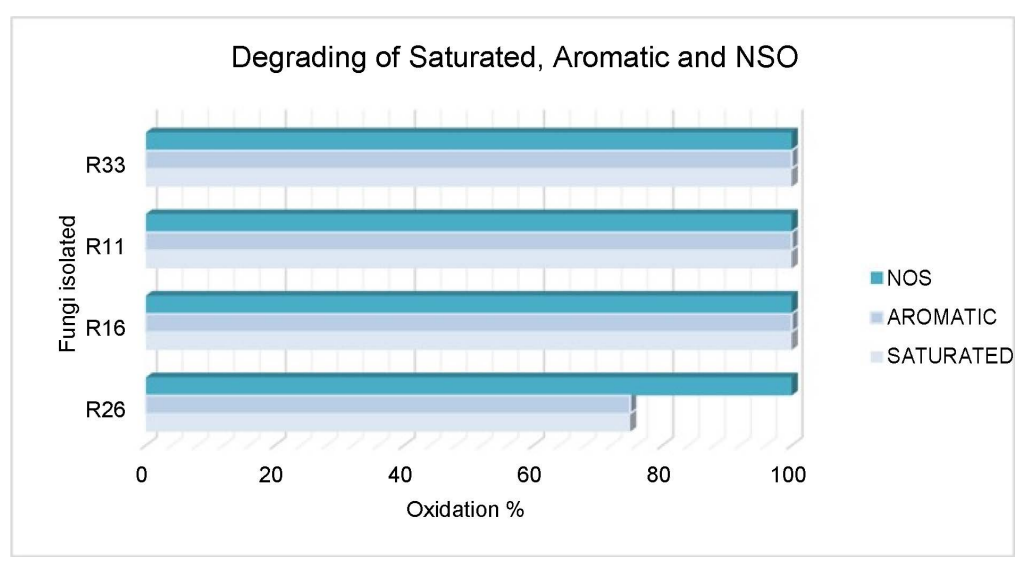

Figure 6. Graph with selected fungi capable of degrading the three fractions in the oil of the Reconcavo basin. 
The same test was conducted with the fungal isolates for oil from the Campos Basin. When the saturated fraction was used as a carbon source, filamentous fungi (R33) after the addition of DCPIP up to completely bleached the tested culture medium (Figure $7(\mathrm{a})$ ). In the presence of the aromatic fraction, fungal isolates R32, R16, R27, A83, A64, A61, A84, A62, A81 and A75 decolorized approximately $50 \%$ to $75 \%$ at 24 hours after the addition of the indicator (Figure 7(b)). Regarding the NSO fraction, isolates R33, R30 and N108 oxidized approximately $50 \%$ to $75 \%$ at 24 hours after the addition of DCPIP, as shown in Figure 7(c).

According to the results, $90 \%$ of the isolates showed the potential to degrade gasoline [19]. Adaptation is the main contributor to the increased hydrocarbon biodegradation capacity. This occurs with some populations of microorganisms in environments polluted by petroleum products [20].

Within 48 hours after the addition of DCPIP, 22 isolates decolorized the medium when using the saturated fraction, where R2, R8, R23, R32, R26, R11, S39, S40, S37 decolorized approximately 75\%; R16, R13, R30, R27, R33, S38, S43, S36, S34, S41, S53 and S52 decolorized 100\% of the medium (Figure 7(a)).

When using the aromatic fraction, R25, A84, A75, and A62 oxidized approximately 50\%; R8, R14, R16, A83, A81, A61 and A64 oxidized approximately 75\%; and R2, R32, R27, R11, A77, A79 and A79R decolorized approximately 100\% (Figure 7(b)).

Regarding the NOS fraction, R13, R30, R31 and N89 oxidized approximately 50\%; R15, N101, and N88 N99R oxidized approximately 75\%; and R2, R25, R14, R32, R8, R26, R33, R11, R16, N108, N82, N96, N87, N100, N104, N89, N103, N85 and N99 decolorized approximately $100 \%$ (Figure 7(c)).

The isolates R24, R23, R14, R25, R1, R15, S48, S49, A74, A74R, A73, A77, A82, A61, A76, A78 N91, N97, N106, N107, N102 and N105 did not test positive for oxidation of the oil fractions from the Recôncavo Basin (Figures 7(a)-(c)).

From the spore counts of the suspensions (Table 2), it was also observed that the capability to oxidize organic compounds is not controlled by the amount of spores produced by the fungal isolates. When comparing the data of Table 2 with Figure 7, it was observed that certain fungi produce many spores and oxidize approximately $50 \%$ to $100 \%$ of the culture medium. For example, the fungus R16 produces $269.5 \times 10^{5}$ spores and oxidizes approximately $100 \%$ of saturated compounds; in contrast, fungus $\mathrm{S} 43$, which produces $4.25 \times 10^{5}$ spores, also oxidizes $100 \%$ of the same compound.

In tests with the oil from the Campos Basin, the fungal isolates were also able to decolorize the culture medium after the addition of DCPIP for all three tested fractions. The isolates R2, R8, R16, R27, R11 and R33 exhibited an oxidative capacity when tested with the three fractions. Of these isolates, R27 and R33 have the most potential and decolorized approximately 100\% (Figure 8). With the tests performed with the fungal isolates of the control samples (ref 01 ), it was possible to select isolates for potential fungal degradation of organic compounds. 

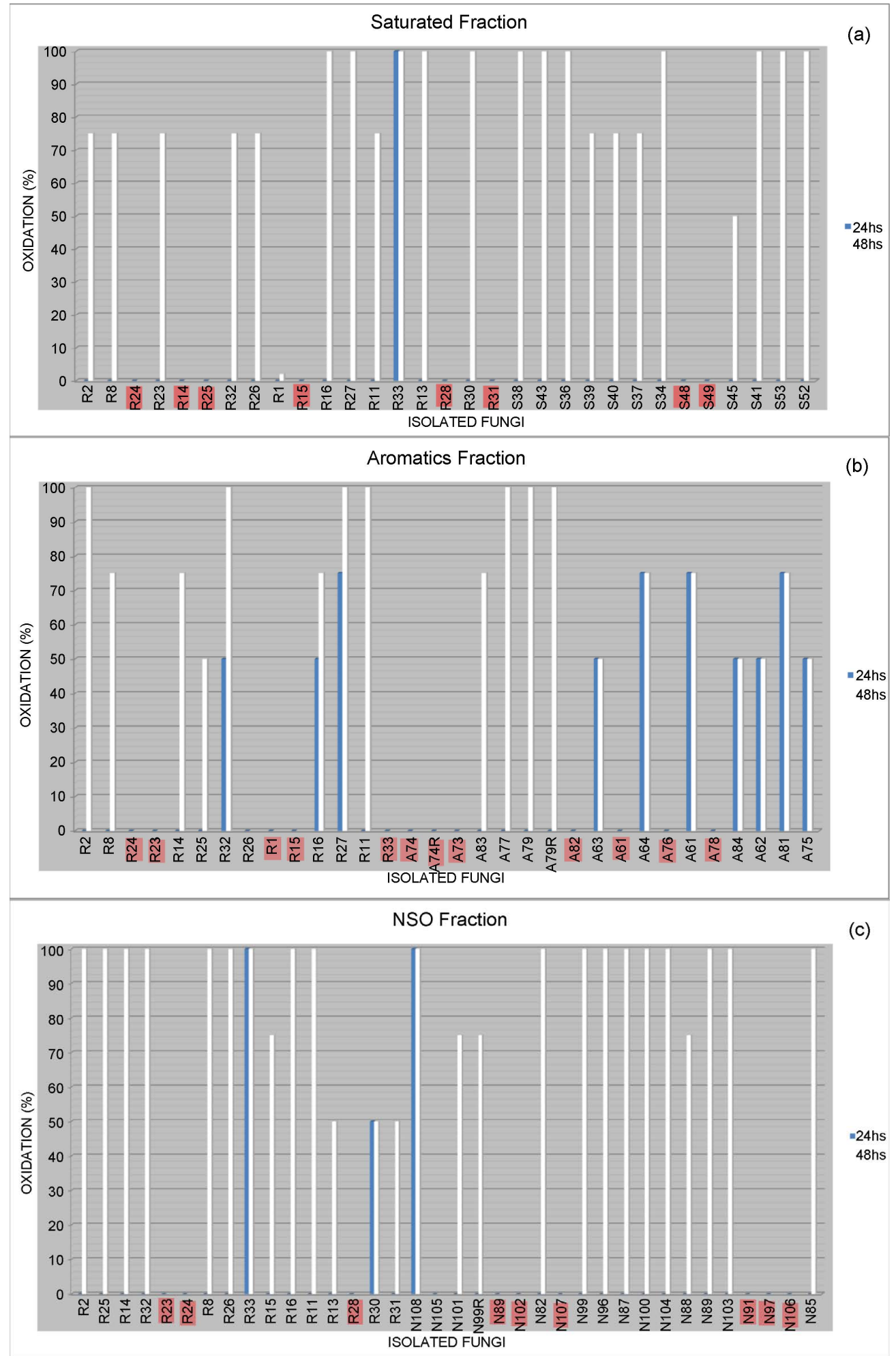

Figure 7. Graph showing the fungi tested for oxidation to the oil in the Campos Basin. (a) Test with saturated fraction; (b) testing with aromatic fraction and (c) with the test fraction NSO.

\subsection{Selection No. 2: 0xidation Test with Acclimatization}

In the oxidation test with the oil fractions of the Recôncavo Basin, performed for each isolate in duplicate, it was observed that 17 of the 19 isolates tested showed 
Table 2. Spores of quantitative values used in the oxidation test for the Campos Basin oil fractions.

\begin{tabular}{cccccc}
\hline SAT & Spores $\left(\right.$ UFC $\left.\times 10^{5}\right)$ & ARO & Spores $\left(\right.$ UFC $\left.\times 10^{5}\right)$ & NSO & Spores $\left(\right.$ UFC $\left.\times 10^{5}\right)$ \\
\hline R2 & 83.75 & R2 & 83.75 & R2 & 83.75 \\
R8 & 56.75 & R8 & 56.75 & R25 & 26.50 \\
R23 & 39.25 & R14 & 44.00 & R14 & 44.00 \\
R32 & 1.25 & R25 & 26.50 & R32 & 1.25 \\
R26 & 29.00 & R32 & 1.25 & R8 & 56.75 \\
R1 & 2.50 & R33 & 0.00 & R26 & 29.00 \\
R16 & 269.5 & R16 & 269.50 & R33 & 0.00 \\
R27 & 50.00 & R27 & 50.00 & R15 & 8.25 \\
R11 & 169.00 & R11 & 169.00 & R16 & 269.5 \\
R33 & 0.00 & A83 & 250.00 & R11 & 169.00 \\
R13 & 25.75 & A77 & 0.00 & R13 & 25.75 \\
R30 & 153.5 & A 79 & 1.00 & R30 & 153.50 \\
S38 & 175.50 & A 79R & 1.00 & R31 & 5.25 \\
S43 & 4.25 & A63 & 310.50 & N94 & 1.50 \\
S36 & 134.25 & A64 & 61.25 & N101 & 57.75 \\
S39 & 31.00 & A61 & 324.00 & N99R & 124.75 \\
S40 & 6.00 & A84 & 89.50 & N82 & 0.00 \\
S37 & 282.75 & A62 & 6.00 & N99 & 0.00 \\
S34 & 5.00 & A81 & 45.25 & N96 & 0.75 \\
S45 & 47.00 & A75 & 94.50 & N87 & 51.25 \\
S41 & 44.25 & - & - & N100 & 1.00 \\
S53 & 193.00 & - & - & N104 & 11.75 \\
S52 & 86.50 & - & - & N88 & 8.50 \\
- & - & - & N89 & 56.00 \\
- & & & - & & 133.75 \\
\hline & & & & & \\
\hline
\end{tabular}

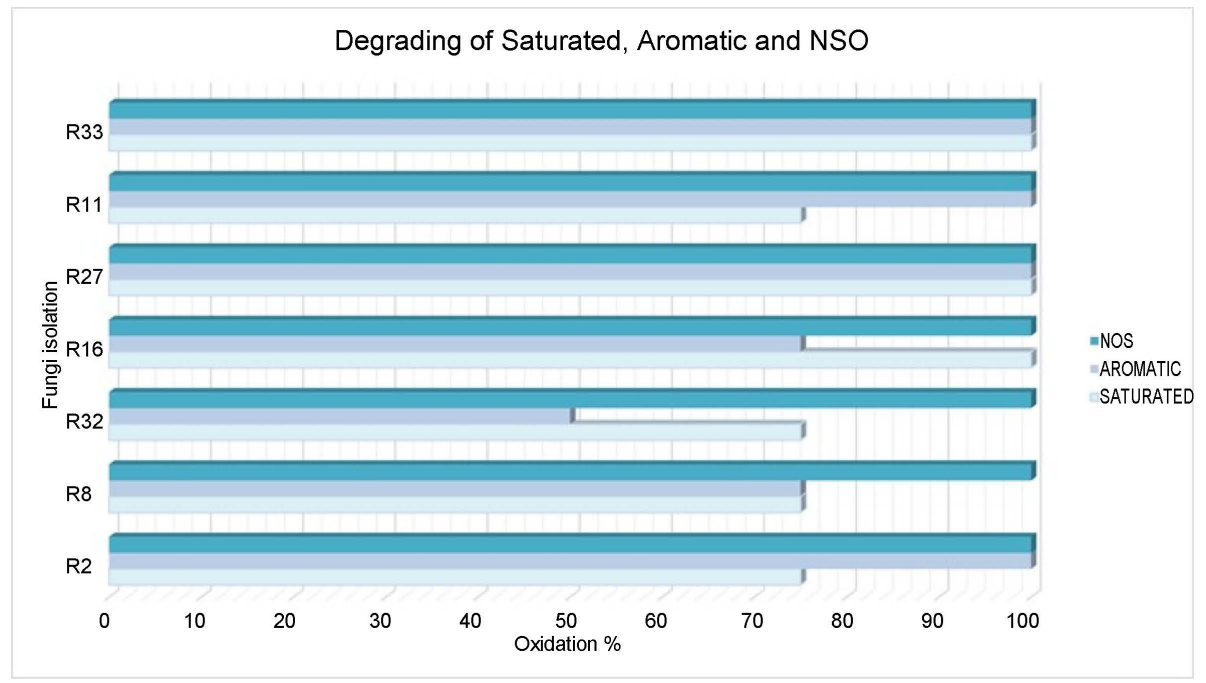

Figure 8. Graphic with selected fungi capable of degrading the three fractions in the oil in the Campos Basin. 
the ability to degrade the saturated fraction after 12 hours, four isolates (R2, R16, R28 and S38) oxidized approximately 50\%, three (R27, R31 and R33) decolorized approximately $25 \%$, four (R11, R30, S45, and S53) oxidized approximately $75 \%$, and six (R32, R26, S36, S39, S40 and S41) oxidized 100\% in the first 12 hours (Figure 9(a)).

With the ability to degrade the aromatic fraction after 12 hours, 15 of the 16 isolates showed the ability to oxidize. Of these, two (A76 and A62) oxidized approximately 50\%, seven (R2, R26, R1, A79, A79R, A63 and A80) decolorized

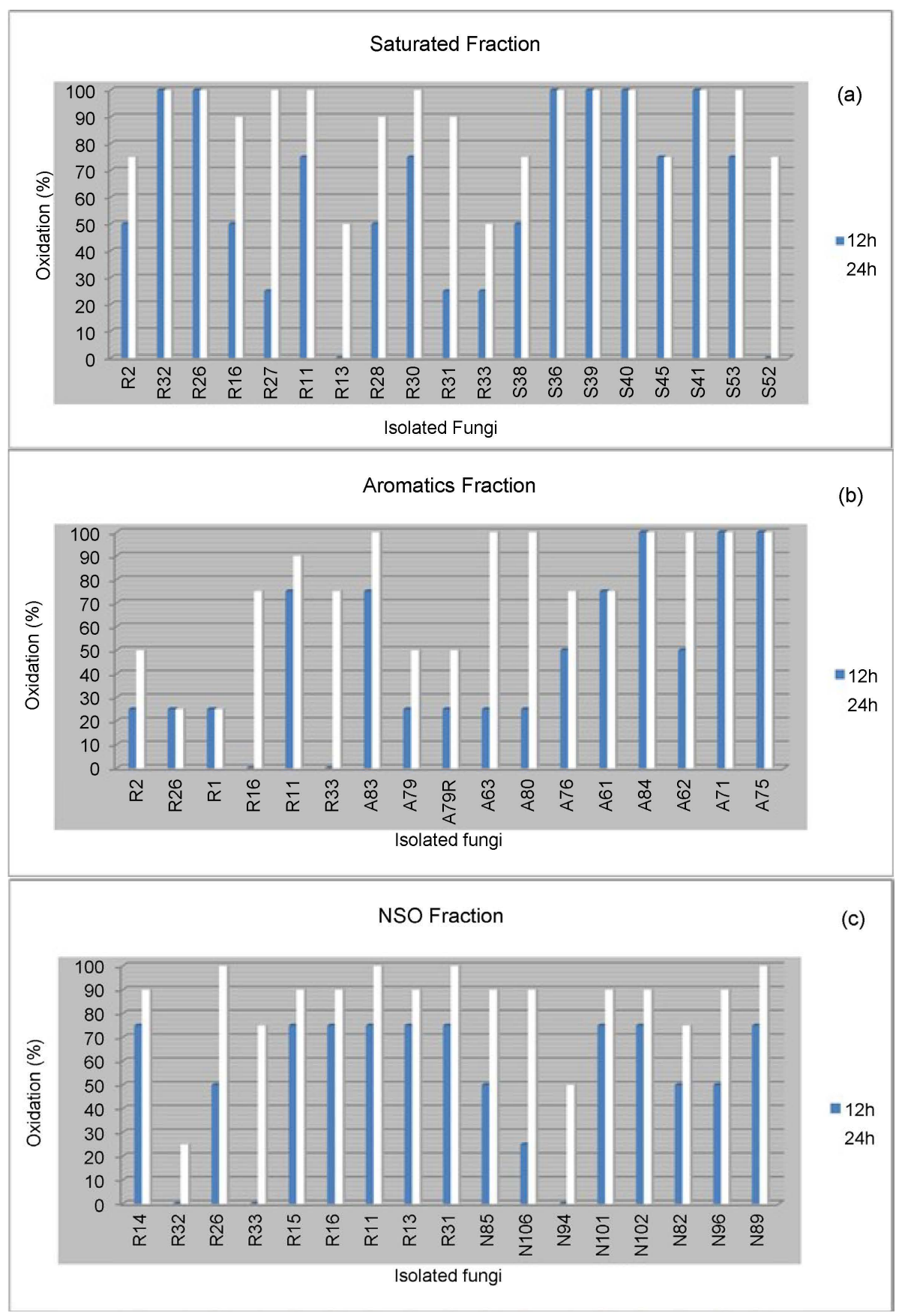

Figure 9. Graph showing the fungi tested for oxidation to oil Reconcavo Basin. (a) Test with saturated fraction; (b) testing with aromatic fraction and (c) with the test fraction NSO. 
approximately $25 \%$, three (R11, A83, and A61) oxidized approximately $75 \%$, and three (A84, A81 and A75) oxidized 100\% in the first 12 hours (Figure 9(b)).

With respect to the isolates tested with the NSO fraction, 14 of the 16 strains showed the ability to oxidize, four (R26, N85, N82 and A96) oxidized approximately 50\%, one (N108) bleached approximately $25 \%$, nine (R14, R15, R16, R11, R13, R31, N101, N102, and N89) oxidized approximately 75\%, and no fungus showed the ability to oxidize $100 \%$ in the first 12 hours (Figure 9(c)).

When the isolates R27, R11, R30 and R53 were tested with the saturated fraction, complete discoloration occurred after 24 hours (Figure 10). For the aromatic and NSO fractions, four isolates decolorized 100\% after 24 hours.

Only the fungal isolates oxidizing $50 \%$ to $100 \%$ were selected as the most promising for degrading oil and organic compounds. However, one should take into account that all of the isolates have a potential to degrade hydrocarbons because they were isolated from a medium containing oil as the sole carbon source, although their activity may have been less accelerated at the onset of biological oxidation compared with the selected isolates [11] [14] [21] [22].

In the oxidation test with the oil fractions of the Campos Basin, performed for each isolate in duplicate, it was observed that 19 of the 23 isolates tested showed the ability to degrade the saturated fraction after 12 hours. Of these, three (R16, S38, S37 and S34) oxidized approximately 50\%, three (R2, R11 R27e) decolorized approximately 25\%, seven (R1, R33, R30, S43, S39, S52 and S53) oxidized approximately 75\%, and three (R8, S36 and S45) oxidized 100\% in the first 12 hours, thus demonstrating their capacity to adapt to the carbon source (Figure $11(\mathrm{a}))$.

With respect to the isolates tested with the NOS fraction, 23 of the 25 isolates had the ability to oxidize. Of these, five (R14, R8, N103, N82 and N96) oxidized approximately 50\%, six (R2, R26, R16, R31, N85 and N100) decolorized approximately 25\%, the six (R15, R11, R13, N101, N99 and N88) oxidized approximately $75 \%$, and three (N99R, N87 and N104) had the ability to oxidize $100 \%$ in the first 12 hours (Figure 11(c)).

When the isolates R26, R30, S38 S39, S40, S37, S34 and S53 were tested with the saturated fraction, complete discoloration occurred after 24 hours (Figure 11(a)).
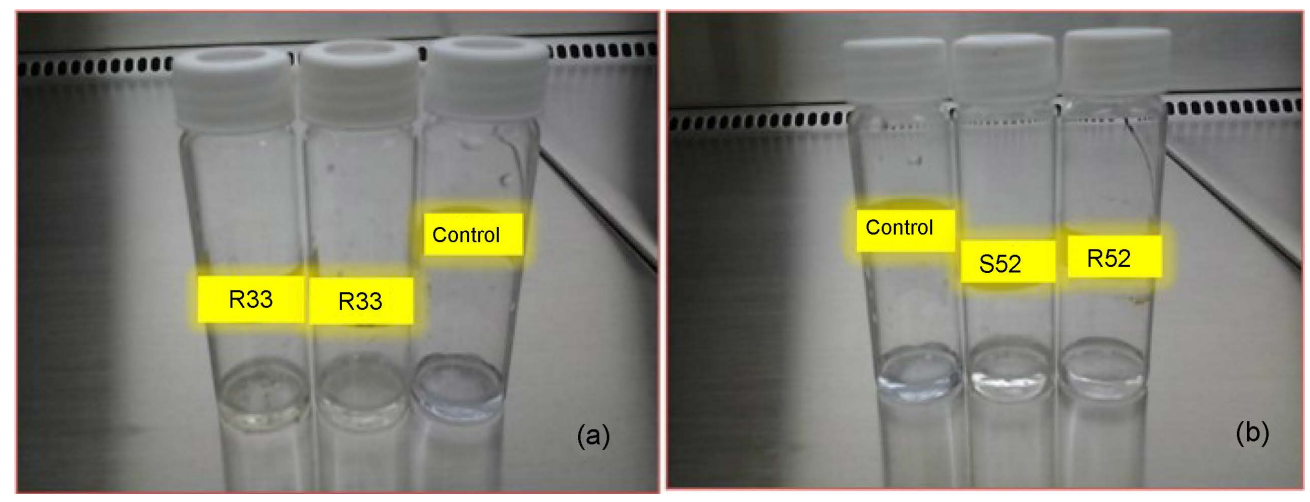

Figure 10. Window color change illustration after 24 hours to two fungi tested for oxidation to oil the Reconcavo Basin. (a) Tests strain with R33 and (b) testing with the S52 strain. 


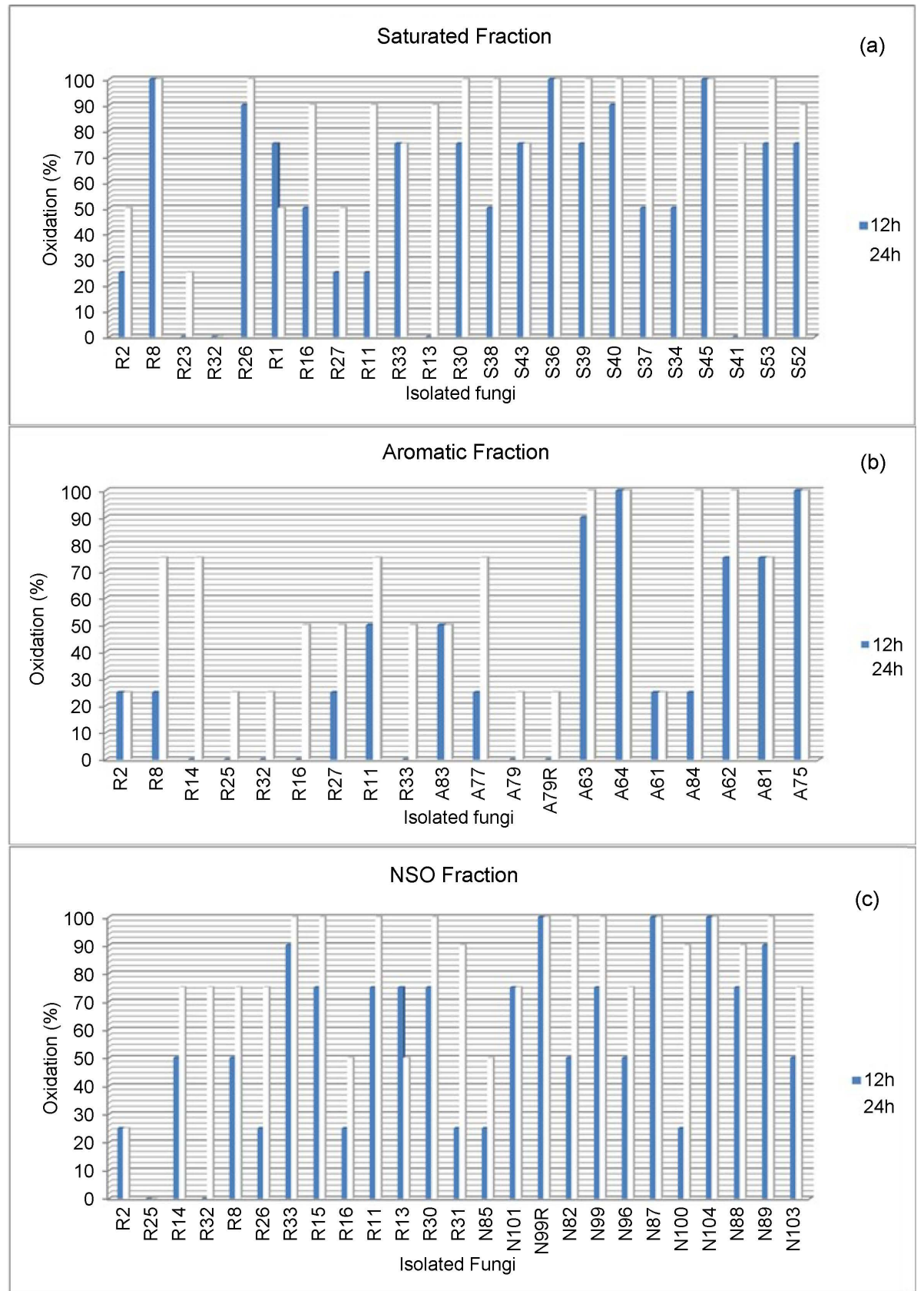

Figure 11. Graph showing the fungi tested for oxidation to oil in the Campos Basin. (a) Test with saturated fraction; (b) testing with aromatic fraction and (c) with the test fraction NSO.

For three aromatic fractions (A63, A84, and A64) and the NSO fraction, seven isolates (R33, R15, R11, R30, N82, N99 and N89) decolorized 100\% after 24 hours (Figure 11(b) and Figure 11(c)).

Only the fungi with oxidative capacities of $50 \%$ to $100 \%$ were selected as the most promising for degrading organic compounds of oil in the Campos Basin, as highlighted in Figures 11(a)-(c).

Three mechanisms can contribute to the adaptation of fungi to the carbon source: induction of specific enzymes, genetic changes that result in the acquisition of new metabolic activities, and selective enrichment of organisms capable 


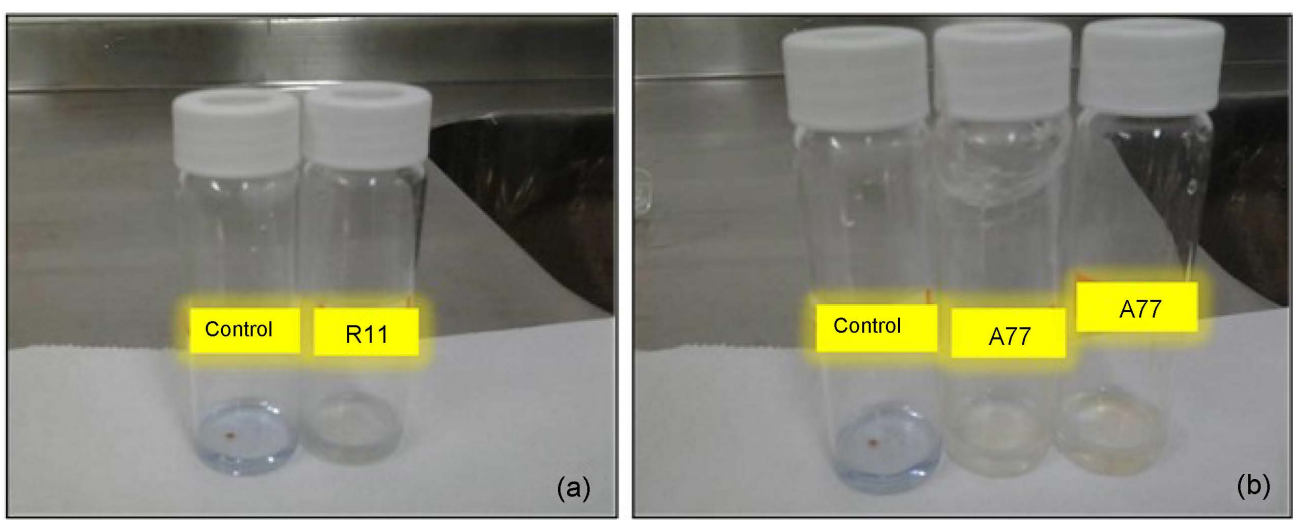

Figure 12. Illustration indicator color change after 24 hours to two fungi tested for oxidation to oil Reconcavo Basin. (a) Test strain with R11 and (b) with the test strain A77.

of transforming the compounds. It is this adjustment that results in an increased rate of degradation of hydrocarbons [19] [23].

Regarding the ability to degrade the aromatic fraction after 12 hours, thirteen of the twenty isolates showed the ability to oxidize, and two (R11 and A83) oxidized approximately 50\%, seven (R2, R8, R27, R11 (Figure 12(a)), A77 (Figure 12(b)), A61 and A84) decolorized approximately 25\%, two (A62 and A81) oxidized approximately 75\%, and two (A64 and A75) oxidized 100\% in the first 12 hours (Figure 12(b)).

\section{Acknowledgements}

The authors acknowledge CNPQ for the scholarship concession and FINEP for the financial support through agreement FINEP-FAPEX n01.05.0016.00, which allowed all phases of this work to be completed. The authors are also grateful to the whole team of the Center for Environmental Studies-NEA (UFBA).

\section{References}

[1] Rodríguez-Martínez, E.M., Pérez, E.X., Schadt, C.W., Zhou, J. and Massol-Deyá, A. (2006) Microbial Diversity and Bioremediation of a Hydrocarbon-Contaminated Aquifer (Vega Baja, Puerto Rico). International Journal of Environmental Research and Public Health, 3, 292-300.

[2] Tabari, K. and Tabari, M. (2010) Biodegradation of Heavy Crude Oil: Effects and Some Innovative Clean-Up Biotechnologies. Journal of Biotechnology, 150, 285 p.

[3] Sonawdekar, S. (2012) Bioremediation: A boon to hydrocarbon degradation. International Journal of Environmental Sciences, 2, 2408-2424.

[4] Van Hamme, J.D., Singh, A. and Ward, O.P. (2003) Recent Advances in Petroleum Microbiology. Microbiology and Molecular Biology Reviews, 67, 503-549.

[5] De Vasconcellos, S.P., Crespim, E., Da Cruz, G.F., Senatore, D.B., Simioni, K.C.M., Dos Santos Neto, E.V. and De Oliveira, V.M. (2009) Isolation, Biodegradation Ability and Molecular Detection of Hydrocarbon Degrading Bacteria in Petroleum Samples from a Brazilian Offshore Basin. Organic Geochemistry, 40, 574-588.

[6] Crisafi, F., Giuliano, L., Yakimov, M.M., Azzaro, M. and Denaro, R. (2016) Isolation and degradation Potential of a Cold-Adapted Oil/PAH-Degrading Marine Bacterial Consortium from Kongsfjorden (Arctic Region). Rendiconti Lincei, 27, 261-270. 
[7] Moustafa, A.M. (2016) Bioremediation of Oil Spill in Kingdom of Saudi Arabia by Using Fungi Isolated from Polluted Soils. International Journal of Current Microbiology and Applied Sciences, 5, 680-691.

[8] UNEP (United Nations Environment Programme) (1991) Determinations of Petroleum Hydrocarbons in Sediments. Reference Methods for Marine Pollution Studies, No.20.

[9] Cooney, J.J., Silver, S.A. and Beck, E.A. (1985) Factors Influencing Hydrocarbon Degradation in Three Freshwater Lakes. Microbial Ecology, 11, 127-137.

[10] Das, N. and Chandran, P. (2010) Microbial Degradation of Petroleum Hydrocarbon Contaminants: An Overview. Biotechnology Research International, 2011, 13 p.

[11] Hanson, K.G., Desai, J.D. and Desai, A.J. (1993) A Rapid and Simple Screening Technique for Potential Crude Oil Degrading Microorganisms. Biotechnology techniques, 7, 745-748.

[12] Cerniglia, C.E. and Perry, J.J. (1973) Crude Oil Degradation by Microorganisms Isolated from the Marine Environment. Zeitschrift für allgemeine Mikrobiologie, 13, 299-306.

[13] Lemos, J.L.S., Rizzo, A.C., Millioli, V.S., Soriano, A.U., De Moura Sarquis, M.I., Santos, R. and Cruz, O. (2002) Petroleum Degradation by Filamentous Fungi. The 9th Annual International Petroleum Environmental Conference, Albuquerque, 22-25 October 2002. http://ipec.utulsa.edu/Conf2002/tech sessions.html

[14] Miranda, R.D.C., Souza, C.S.D., Gomes, E.D.B., Lovaglio, R.B., Lopes, C.E. and Sousa, M.D.F.V.D. (2007) Biodegradation of Diesel Oil by Yeasts Isolated from the Vicinity of Suape Port in the State of Pernambuco-Brazil. Brazilian Archives of Biology and Technology, 50, 147-152.

[15] Gerba, I.L. and Pepper, C.P. (2004) Environmental Microbiology: A Laboratory Manual. In: Pepper, I., Gerba, C. and Brendecke, J., Eds., Examination of Soil Microorganisms via Microscopic and Cultural Assays, Academic Press, Massachusetts, 27-36.

[16] Lima, D.F. Oliveira, O.M.C., Queiroz, A.F.S., Triguis, J.A, Yolanda, C. and Geris, R. (2012) Vacuum Liquid Chromatography for Oil Fractionation. Brazil Patent No. BR 1020120335204 A2. INPI-National Institute of Industrial Property.

[17] Souza, E.S., Triguis, J.A., Barbanti, S.M. and Volpon, A.T. (2003) Oil Bioremediation Processes in Brazilian Marine Environments: Laboratory Simulations. Arctic and Marine Oil Spill Program (AMOP) Technical Seminar, Canada, 6-8 June 2017, 1978-2016.

[18] Miranda, R.D.C., Souza, C.S.D., Gomes, E.D.B., Lovaglio, R.B., Lopes, C.E. and Sousa, M.D.F.V.D. (2007) Biodegradation of diesel Oil by Yeasts Isolated from the Vicinity of Suape Port in the State of Pernambuco-Brazil. Brazilian Archives of Biology and Technology, 50, 147-152.

[19] Souza, C.S., Miranda, R.C.M., Sena, K.X.F.R., Araújo, J.M., Chiappeta, A.D.A. and Sousa, M.F.V.Q. (2005) Isolation and Selection of Microbial Degraders of Petroleum Products. Brazilian Congress of $R$ \& D in Oil and Gas, 8 May 2013. http://www.portalabpg.org.br/site portugues/3 congresso.html

[20] Spain, J.C., Pritchard, P.H. and Bourquin, A.W. (1980) Effects of Adaptation on Biodegradation Rates in Sediment/Water Cores from Estuarine and Freshwater Environments. Applied and Environmental Microbiology, 40, 726-734.

[21] Brown, E.J. and Braddock, J.F. (1990) Sheen Screen, a Miniaturized Most-ProbableNumber Method for Enumeration of Oil-Degrading Microorganisms. Applied and Environmental Microbiology, 56, 3895-3896. 
[22] Braddock, J.F. and Catterall, P.H. (1999) A Simple Method for Enumerating Gasoline and Diesel-Degrading Microorganisms. Bioremediation Journal, 3, 81-84.

[23] Leahy, J.G. and Colwell, R.R. (1990) Microbial Degradation of Hydrocarbons in the Environment. Microbiological Reviews, 54, 305-315.

\section{Scientific Research Publishing}

Submit or recommend next manuscript to SCIRP and we will provide best service for you:

Accepting pre-submission inquiries through Email, Facebook, LinkedIn, Twitter, etc. A wide selection of journals (inclusive of 9 subjects, more than 200 journals)

Providing 24-hour high-quality service

User-friendly online submission system

Fair and swift peer-review system

Efficient typesetting and proofreading procedure

Display of the result of downloads and visits, as well as the number of cited articles

Maximum dissemination of your research work

Submit your manuscript at: http://papersubmission.scirp.org/

Or contact ojogas@scirp.org 